EVIDENCE BASED PUBLIC HEALTH POLICY AND PRACTICE

\title{
Self ratings of health predict functional outcome and recurrence free survival after stroke
}

\author{
T Hillen, S Davies, A G Rudd, T Kieselbach, C D Wolfe
}

J Epidemiol Community Health 2003;57:960-966

See end of article for authors' affiliations

Correspondence to:

Dr C Wolfe, Public Health

Sciences, 5th Floor,

Capital House, Guy's

Hospital, 42 Weston

Street, London SEI 3QD,

UK; charles.wolfe@

kcl.ac.uk

Accepted for publication 16 May 2003

\begin{abstract}
Study objective: To measure stroke victims' self rated health (SRH) status and SRH transition, and to compare how the two are prospectively associated with disability and recurrence free survival.

Design: Prospective case registry study with face to face follow up interviews at three months, one, two, and three years. Ascertained were SRH status and SRH transition using single question assessments, Barthel Index (BI), Frenchay Activities Index (FAI), and Mini Mental State Examination (MMSE).

Setting: A multiethnic inner city population of 234533.

Participants: Patients surviving the initial three months after a first in a lifetime stroke in 1995 to 1998.

Results: Of 690 stroke survivors 561 (81.3\%) could complete the self report items. Answers to the item on SRH status did not vary significantly between the four follow up interviews. However, responses to the item on SRH transition changed significantly during follow up with three months ratings being more negative than all subsequent ratings. SRH transition, but not SRH status, showed a prospective association with long term outcome in multivariate analyses controlling for the BI, FAl, and MMSE. Compared with all other patients, patients reporting "Much worse health" at three months were more likely to be disabled $(=\mathrm{Bl}<20)$ at one year $(\mathrm{OR} 6.29,95 \% \mathrm{Cl} 2.26$ to 17.52$)$ and their combined risk of stroke recurrence and death was increased over five years (HR 1.72,95\% $\mathrm{Cl} 1.25$ to 2.38 ).

Conclusions: Items on SRH should be used with caution in populations with high rates of disability and language problems, as many participants are unable to complete them. SRH transition may be a better predictor of disability and recurrence free survival after major medical events than SRH status.
\end{abstract}

$\mathrm{S}$ elf rated health (SRH) is a widely used measure of global health in epidemiological studies, as it provides direct information on the person's health perceptions, is easily obtained, and prospectively associated with health care service use and mortality. ${ }^{1-4}$ New studies have been demanded that examine SRH in special populations, permit comparisons between ethnic groups, and relate it to other outcome measures such as recurrence of disease and disability. ${ }^{4}$

Although stroke is the disease with largest impact on SRH in individual patients, ${ }^{5}$ this indicator has not been examined in a cohort of stroke patients to date. Rates of recurrences and disability are high in the stroke population. ${ }^{67}$ Therefore, this patient group is ideal to study the relation between SRH and other important outcome measures.

Previous research in stroke medicine has predominantly focused on functional outcome using measures such as the Barthel Index (BI) and the Frenchay Activities Index (FAI). ${ }^{6}$ Other authors have emphasised the need for more global measures, which take the health related quality of life and the patients' own perceptions into account. ${ }^{78}$ Items on SRH may provide some basic information in this regard. Furthermore, few data exist on the long term outcome after stroke as most of the publications report on follow up periods of up to one year. ${ }^{6-11}$

Most researchers have used items on SRH that investigate the health status (that is, excellent to poor health) at the time of interview and do not take into account the trajectory of health. However, these items have been reported to be comparatively insensitive to major medical events. ${ }^{12}$ Items on SRH transition might be a useful supplement as they ask about health changes (that is, much better to much worse health) and therefore tap into the adjustment process to disease and disability. Systematic comparisons between SRH status and SRH transition are lacking.
This population based study compares SRH status and SRH transition in a multiethnic cohort of stroke patients. It investigates how stroke patients rate their health over a follow up period of three years. The prospective association of SRH status and SRH transition with two other outcome measures, disability, and recurrence free survival, is analysed.

\section{METHODS}

\section{Case ascertainment}

The population based South London Community Stroke Register, established in 1995, prospectively collects data on first in a lifetime strokes in patients of all age groups. The methodology has been described in detail elsewhere and is summarised here. ${ }^{13}{ }^{14}$ Twelve overlapping referral sources are used to attain complete notification of such strokes in the study area. The study area compromises 22 wards of the Lambeth, Southwark and Lewisham Health Authority (LSLHA) with a population of 234533 . Stroke was defined according to the WHO criteria. ${ }^{15}$ The diagnosis of stroke and the initial assessment was made by one of the study doctors within the first week after the event where possible. The study includes patients registered between 1995 and 1998. The study was approved by an ethics committee and has conformed to the principles embodied in the Declaration of Helsinki.

\section{Pre-stroke and acute stroke data}

Demographic factors analysed in this study include age, sex, and ethnicity. Recording of ethnicity was based on census categories. ${ }^{13}$ Patients of African-Caribbean $(\mathrm{n}=75)$ and

Abbreviations: SRH, self rated health; FAl, Frenchay Acitivities Index; MMSE, Mini Mental state Examination; BI, Barthel Index 
Table 1 Comparison between three month stroke survivors that were included and three month stroke survivors that were excluded in this study

\begin{tabular}{llll}
\hline & $\begin{array}{l}\text { Patients included } \\
(\mathbf{n = 5 6 1 )}\end{array}$ & $\begin{array}{l}\text { Patients excluded } \\
(\mathbf{n = 2 0 7 )}\end{array}$ & p Value \\
\hline Age, years (SD) & $69.4(13.7)$ & $71.5(13.4)$ & $0.06^{*}$ \\
Male sex, $\mathrm{n}(\%)$ & $297(52.9)$ & $100(48.3)$ & $0.25 \dagger$ \\
African/Caribbean origin, $\mathrm{n}(\%)$ & $102(18.2)$ & $34(16.4)$ & $0.57 \dagger$ \\
Haemorrhagic stroke, $\mathrm{n}(\%)$ & $88(15.7)$ & $31(15.0)$ & $0.81 \dagger$ \\
Glasgow coma score $\leqslant 13, \mathrm{n}(\%)$ & $69(12.3)$ & $57(27.5)$ & $<0.01 \dagger$ \\
Dysphasia, $\mathrm{n}(\%)$ & $98(17.5)$ & $81(39.1)$ & $<0.01 \dagger$ \\
Barthel Index before stroke $\leqslant 19, \mathrm{n}(\%)$ & $114(20.3)$ & $55(26.6)$ & $0.06 \dagger$ \\
Frenchay Activities Index before & $85(15.2)$ & $52(25.1)$ & $<0.01 \dagger$ \\
stroke $\leqslant 15, \mathrm{n}(\%)$ & & & \\
\hline \multirow{2}{*}{$t$ test; $\dagger \chi^{2}$ test. } & & & \\
\hline
\end{tabular}

African ( $\mathrm{n}=27$ ) origin were classified as "black", patients of white $(n=437)$ and other $(n=22)$ origin as "white or other". The patients' functional status before their stroke was assessed with the BI and FAI, which were completed during the initial assessment. When the patient was not able to cooperate, proxies were interviewed. ${ }^{6}{ }^{16}$ The BI is a widely adopted instrument to ascertain disabilities in basic activities of daily living such as having a bath and feeding, whereas the FAI is a measure of instrumental activities of daily living at and outside the home and of social functioning. Patients with a BI $\leqslant 19$ were classified as "disabled" and with a FAI $\leqslant 15$ as "inactive". ${ }^{17}{ }^{18}$ Subtype of stroke was classified as in the Oxford Community Stroke Project and divided into "cerebral infarction/unclassified stroke" and "intracerebral haemorrhage/subarachnoidal haemorrhage". ${ }^{19}$ Stroke severity was assessed by the lowest documented Glasgow Coma Score and patients were dichotomised into scores of $\leqslant 13$ or higher. ${ }^{20}$

\section{Follow up data}

The South London Community Stroke Register undertakes follow up interviews with the patients three months, one year, and three years after stroke. A follow up at two years was made only with the initial 1995 cohort. Hence, for this study data on all of the four follow ups were available for the 1995 cohort; three months and one year data could be included for the 1996 and 1997 cohort; and three months data for the 1998 cohort.

SRH was obtained at each follow up. SRH status was assessed by the following question. "In general, would you say your health is: excellent-very good-good-fair-poor." SRH transition was measured with the following question.
"Compared to one year ago, how would you rate your health in general now? Much better-somewhat betterabout the same-somewhat worse-much worse." At one year follow up patients were asked to make a comparison of their health to before the stroke. At three months follow up cognitive function was assessed by the Mini Mental State Examination (MMSE-cut off at 24 points).

Death was notified to the register from the Office for National Statistics (ONS). Registration of stroke recurrence was performed in the same way as for the index stroke. The definition of stroke recurrence was the same as for first stroke with additional criteria ${ }^{21}$ : there had to be either a new neurological deficit or a deterioration of the previous deficit not considered to be attributable to oedema, haemorrhagic transformation, or intercurrent illness. Only recurrences 21 days after the index stroke or, if earlier, clearly in another vascular territory were included.

\section{Statistics}

Changes in SRH status and SRH transition during follow up were analysed with the Wilcoxon matched pairs signed ranks test and all subsequent self ratings were compared with those given at three months. Cross sectional univariate associations of patient characteristics with SRH status and SRH transition were examined by ordered logistic regression. Multivariate analysis of the relation between SRH at three months and disability at one year was done by logistic regression. At first a model for the control variables was fitted including demographic details (age, sex, ethnicity) and the pre-stroke BI and FAI. In the next step either SRH status or SRH

Table 2 Self rated health status and self rated health transition among stroke patients up to three years after the event, $\mathrm{n}(\%)$

\begin{tabular}{|c|c|c|c|c|c|c|c|}
\hline & \multicolumn{4}{|l|}{ Three months } & \multirow{3}{*}{$\begin{array}{l}\text { One year } \\
(n=356)\end{array}$} & \multirow{3}{*}{$\begin{array}{l}\text { Two years } \\
(n=97)\end{array}$} & \multirow{3}{*}{$\begin{array}{l}\text { Three years } \\
(n=86)\end{array}$} \\
\hline & \multirow{2}{*}{$\begin{array}{l}\text { Full sample } \\
(n=561)\end{array}$} & \multicolumn{3}{|c|}{ Subsamples for matched pairs tests } & & & \\
\hline & & $(n=356)$ & $(n=97)$ & $(n=86)$ & & & \\
\hline \multicolumn{8}{|l|}{ Self rated health status } \\
\hline Excellent & $27(4.8)$ & $14(3.9)$ & $3(3.1)$ & $3(3.5)$ & $21(5.9)$ & $6(6.2)$ & $5(5.8)$ \\
\hline Very good & $104(18.5)$ & $67(18.8)$ & $21(21.6)$ & $19(22.1)$ & 53 (14.9) & $10(10.3)$ & $15(17.4)$ \\
\hline Good & $198(35.3)$ & $128(36.0)$ & $34(35.1)$ & $31(36.0)$ & $140(39.3)$ & $36(37.1)$ & $31(36.0)$ \\
\hline Fair & $149(26.6)$ & $99(27.8)$ & $26(26.8)$ & $23(26.7)$ & $89(25.0)$ & $28(28.9)$ & $26(30.2)$ \\
\hline Poor & $83(14.8)$ & $48(13.5)$ & $13(13.4)$ & $10(11.6)$ & $53(14.9)$ & $17(17.5)$ & $9(10.5)$ \\
\hline $\begin{array}{l}\mathrm{p}^{*} \text { (versus three months) } \\
\text { Self rated health transition }\end{array}$ & & & & & 0.90 & 0.11 & 1.00 \\
\hline Much better & $16(2.9)$ & $14(3.9)$ & $7(7.2)$ & $8(9.3)$ & $43(12.1)$ & $4(4.1)$ & $4(4.7)$ \\
\hline Somewhat better & $47(8.4)$ & $28(7.9)$ & $6(6.2)$ & $5(5.8)$ & $103(28.9)$ & $28(28.9)$ & $18(20.9)$ \\
\hline About the same & $183(32.6)$ & $122(34.3)$ & $27(27.8)$ & $27(31.4)$ & $114(32.0)$ & $51(52.6)$ & $44(51.2)$ \\
\hline Somewhat worse & $197(35.1)$ & $129(36.2)$ & $39(40.2)$ & $29(33.7)$ & $68(19.1)$ & $9(9.3)$ & $17(19.8)$ \\
\hline Much worse & $118(21.0)$ & $63(17.7)$ & $18(18.6)$ & $17(19.8)$ & $28(7.9)$ & $5(5.2)$ & $3(3.5)$ \\
\hline $\mathrm{p}^{*}$ (versus three months) & & & & & $<0.01$ & $<0.01$ & $<0.01$ \\
\hline
\end{tabular}

*Wilcoxon matched pairs signed ranks test. The three months data of those who also participated in the one, two, and three year interview are given separately. 
Table 3 Univariate cross sectional association between patient characteristics and self rated health status three months after stroke, number (\%)

\begin{tabular}{|c|c|c|c|c|c|c|c|}
\hline & \multirow{2}{*}{$\begin{array}{l}\text { Number } \\
561\end{array}$} & \multicolumn{5}{|c|}{ Self rated health status three months after stroke } & \multirow[b]{2}{*}{$\mathbf{p}^{*}$} \\
\hline & & Excellent & Very good & Good & Fair & Poor & \\
\hline Age & & & & & & & 0.03 \\
\hline$\leqslant 75$ years & 340 & $14(4.1)$ & 55 (16.2) & $120(35.3)$ & $97(28.5)$ & $54(15.9)$ & \\
\hline$>75$ years & 221 & $13(5.9)$ & $49(22.2)$ & $78(35.3)$ & $52(23.5)$ & $29(13.1)$ & \\
\hline Sex & & & & & & & 0.15 \\
\hline Male & 297 & $13(4.4)$ & $60(20.2)$ & $109(36.7)$ & $78(26.3)$ & $37(12.5)$ & \\
\hline Female & 264 & $14(5.3)$ & $44(16.7)$ & $89(33.7)$ & $71(26.9)$ & $46(17.4)$ & \\
\hline Ethnic group & & & & & & & 0.01 \\
\hline White/other & 459 & $25(5.4)$ & $90(19.6)$ & $162(35.3)$ & $121(26.4)$ & $61(13.3)$ & \\
\hline Black & 102 & $2(2.0)$ & 14 (13.7) & $36(35.3)$ & $28(27.5)$ & $22(21.6)$ & \\
\hline Stroke subtype & & & & & & & 0.96 \\
\hline Infarction & 473 & $22(4.7)$ & 92 (19.5) & $163(34.5)$ & $123(26.0)$ & $73(15.4)$ & \\
\hline Haemorrhage & 88 & $5(5.7)$ & $12(13.6)$ & $35(39.8)$ & $26(29.5)$ & $10(11.4)$ & \\
\hline Glasgow Coma Score & & & & & & & 0.85 \\
\hline 14 to 15 & 492 & $23(4.7)$ & 88 (17.9) & $180(36.6)$ & $128(26.0)$ & 73 (14.8) & \\
\hline$\leqslant 13$ & 69 & $4(5.8)$ & $16(23.2)$ & $18(26.1)$ & $21(30.4)$ & $10(14.5)$ & \\
\hline $\begin{array}{l}\text { Barthel Index before } \\
\text { stroke }\end{array}$ & & & & & & & $<0.01$ \\
\hline Not disabled (=20) & 447 & $24(5.4)$ & 85 (19.0) & $174(38.9)$ & $114(25.5)$ & $50(11.2)$ & \\
\hline Disabled ( $\leqslant 19)$ & 114 & $3(2.6)$ & 19 (16.7) & $24(21.1)$ & $35(30.7)$ & $33(28.9)$ & \\
\hline $\begin{array}{l}\text { Barthel Index at three } \\
\text { months }\end{array}$ & & & & & & & $<0.01$ \\
\hline Not disabled (=20) & 238 & $14(5.9)$ & $61(25.6)$ & $94(39.5)$ & $53(22.3)$ & $16(6.7)$ & \\
\hline Disabled $(\leqslant 19)$ & 323 & $13(4.0)$ & 43 (13.3) & $104(32.2)$ & $96(29.7)$ & $67(20.7)$ & \\
\hline $\begin{array}{l}\text { Frenchay Activities } \\
\text { Index before stroke }\end{array}$ & & & & & & & $<0.01$ \\
\hline Active (0-15) & 476 & $24(5.0)$ & $92(19.3)$ & $179(37.6)$ & $122(25.6)$ & 59 (12.4) & \\
\hline Inactive $(16-30)$ & 85 & $3(3.5)$ & $12(14.1)$ & $19(22.4)$ & $27(31.8)$ & $24(28.2)$ & \\
\hline $\begin{array}{l}\text { Frenchay Activities } \\
\text { Index at three months }\end{array}$ & & & & & & & $<0.01$ \\
\hline Active (0-15) & 233 & $17(7.3)$ & $54(23.2)$ & $94(40.3)$ & $50(21.5)$ & $18(7.7)$ & \\
\hline Inactive $(16-30)$ & 328 & $10(3.0)$ & $50(15.2)$ & $104(31.7)$ & $99(30.2)$ & $65(19.8)$ & \\
\hline $\begin{array}{l}\text { Mini Mental State } \\
\text { examination at three } \\
\text { months }\end{array}$ & & & & & & & $<0.01$ \\
\hline$\geqslant 24$ & 329 & $19(5.8)$ & $71(21.6)$ & $125(38.0)$ & $83(25.2)$ & $31(9.4)$ & \\
\hline$<24$ & 232 & $8(3.5)$ & $33(14.2)$ & $73(31.5)$ & $66(28.5)$ & $52(22.4)$ & \\
\hline
\end{tabular}

transition was added to the model. Finally, the three months BI, FAI, and MMSE were added. For analysis of recurrence free survival Cox regression analysis was used and the same modelling steps as in the logistic regression analysis were used.

\section{RESULTS}

\section{Sample description}

The number of patients registered on the South London Community Stroke Register between the l January 1995 and end of 1998 was 1147, of whom 768 (67\%) survived the first three months after stroke. Among the survivors $690(89.8 \%)$ underwent the three months follow up, $78(10.2 \%)$ stroke patients refused to participate or could not be traced. At three months follow up 129 (18.7\%) participants were unable to complete self report items because of severe illness, aphasia, or limited command of English and only basic information could be obtained from informants. Hence, a total of 561 stroke patients were available for the analysis of the three months data. Response rates to self report items at one, two, and three years after index stroke were 356 (81.7\%), $97(79.5 \%)$, and $86(81.9 \%)$ respectively among eligible participants.

Table 1 permits a comparison between the 561 patients included in the present analysis and those patients who, despite having survived the first three months, could not be included. The second group tended to have a lower pre-stroke level of functioning, more severe strokes, and more often suffered with dysphasia than the first group.

\section{Self rated health in stroke patients over a three year} period

Table 2 gives SRH status and SRH transition over a three year period after stroke. The longitudinal comparisons were based on matched pairs tests. The three months data are given separately for those patients who also completed the one, two, and three year follow up and therefore were included in matched pairs tests. There was no significant change in the patients' SRH status during follow up. SRH transition, however, varied significantly over time. Patients tended to report more unfavourable health transitions at three months compared with any of the later annual follow ups.

\section{Cross sectional associations of self rated health}

The univariate associations between patient characteristics and SRH status at three months are shown in table 3. Age over 75 years, white/other ethnicity, absence of pre-stroke disability, and inactivity were related to more favourable SRH status. While the acute stroke parameters (subtype and GCS) showed no association with SRH status, the other objective three months outcome measures (BI, FAI, MMSE) did. Table 4 displays the analogous results for SRH transition, which differed only slightly from those for SRH status.

\section{Prospective univariate associations of self rated health}

Among the 356 stroke patients, who participated in the one year follow up, $189(53.1 \%)$ were disabled $(\mathrm{BI} \leqslant 19)$. Patients with unfavourable SRH status or SRH transition at three months were significantly more often disabled at one year (table 5). However, the rates of recurrence free survival at one 
Table 4 Univariate cross sectional association between patient characteristics and self rated health transition three months after stroke, number $(\%)$

\begin{tabular}{|c|c|c|c|c|c|c|c|}
\hline & \multirow{2}{*}{$\begin{array}{l}\text { Number } \\
561\end{array}$} & \multicolumn{5}{|c|}{ Self rated health transition three months after stroke } & \multirow[b]{2}{*}{$\mathbf{p}^{*}$} \\
\hline & & Much better & Somewhat befter & About the same & Somewhat worse & Much worse & \\
\hline Age & & & & & & & 0.03 \\
\hline$\leqslant 75$ years & 340 & $10(2.9)$ & $26(7.6)$ & $98(28.8)$ & $129(37.9)$ & $77(22.6)$ & \\
\hline$>75$ years & 221 & $6(2.7)$ & $21(9.5)$ & $85(38.5)$ & $68(30.8)$ & 41 (18.6) & \\
\hline Sex & & & & & & & 0.25 \\
\hline Male & 297 & $9(3.0)$ & $30(10.1)$ & $95(32.0)$ & $105(35.4)$ & $58(19.5)$ & \\
\hline Female & 264 & $7(2.7)$ & $17(6.4)$ & 88 (33.3) & $92(34.8)$ & $60(22.7)$ & \\
\hline Ethnic group & & & & & & & 0.03 \\
\hline White/other & 459 & $12(2.6)$ & $40(8.7)$ & $160(34.9)$ & $157(34.2$ & $90(19.6)$ & \\
\hline Black & 102 & $4(3.9)$ & $7(6.9)$ & $23(22.5)$ & ) 40 (39.3) & $28(27.5)$ & \\
\hline Stroke subtype & & & & & & & 0.19 \\
\hline Infarction & 473 & $13(2.7)$ & $37(7.8)$ & $154(32.6)$ & $165(34.9)$ & $104(22.0)$ & \\
\hline Haemorrhage & 88 & $3(3.4)$ & $10(11.4)$ & $29(33.0)$ & $32(36.4)$ & $14(15.9)$ & \\
\hline Glasgow Coma Score & & & & & & & 0.78 \\
\hline 14 to 15 & 492 & $14(2.8)$ & $37(7.5)$ & $161(32.7)$ & $182(37.0)$ & $98(19.9)$ & \\
\hline$\leqslant 13$ & 69 & $2(2.9)$ & $10(14.5)$ & $22(31.9)$ & $15(21.7)$ & $20(29.0)$ & \\
\hline \multicolumn{7}{|c|}{ Barthel Index before stroke } & 0.02 \\
\hline Not disabled $(=20)$ & 447 & $14(3.1)$ & $36(8.1)$ & $152(34.0)$ & $165(36.9)$ & $80(17.9)$ & \\
\hline Disabled $(\leqslant 19)$ & 114 & $2(1.8)$ & $11(9.6)$ & $31(27.2)$ & $32(28.1)$ & 38 (33.3) & \\
\hline $\begin{array}{l}\text { Barthel Index at three } \\
\text { months }\end{array}$ & & & & & & & $<0.01$ \\
\hline Not disabled (=20) & 238 & $8(3.4)$ & $23(9.7)$ & $96(40.3)$ & $86(36.1)$ & $25(10.5)$ & \\
\hline Disabled $(\leqslant 19)$ & 323 & $8(2.5)$ & $24(7.4)$ & $87(26.9)$ & $111(34.4)$ & $93(28.8)$ & \\
\hline $\begin{array}{l}\text { Frenchay Activities Index } \\
\text { before stroke }\end{array}$ & & & & & & & 0.23 \\
\hline Active (0-15) & 476 & $15(3.2)$ & $37(7.8)$ & $157(33.0)$ & $177(37.2)$ & $90(18.9)$ & \\
\hline Inactive $(16-30)$ & 85 & $1(1.2)$ & $10(11.8)$ & $26(30.6)$ & $20(23.5)$ & $28(32.9)$ & \\
\hline \multicolumn{7}{|c|}{$\begin{array}{l}\text { Frenchay Activities Index at } \\
\text { three months }\end{array}$} & $<0.01$ \\
\hline Active (0-15) & 233 & $6(2.6)$ & $24(10.3)$ & $94(40.3)$ & $88(37.8)$ & $21(9.0)$ & \\
\hline Inactive $(16-30)$ & 328 & $10(3.0)$ & $23(7.0)$ & $89(27.1)$ & $109(33.2)$ & $97(29.6)$ & \\
\hline $\begin{array}{l}\text { Mini Mental State } \\
\text { examination at three } \\
\text { months }\end{array}$ & & & & & & & $<0.01$ \\
\hline$\leqslant 24$ & 329 & $11(3.3)$ & $28(8.5)$ & $116(35.3)$ & $125(38.0)$ & $49(14.9)$ & \\
\hline$<24$ & 232 & $5(2.2)$ & $19(8.2)$ & $67(28.9)$ & $72(31.0)$ & $69(29.7)$ & \\
\hline
\end{tabular}

year showed only a significant association with SRH transition and not with SRH status.

\section{Prospective multivariate associations of self rated health with one year disability and recurrence free survival}

All multivariate models controlled for the demographic variables, pre-stroke BI and pre-stroke FAI. "Poor health" and "much worse health" respectively were contrasted with the remaining categories, as the differences between the remaining categories were minimal as evidenced by similar $\beta$ coefficients in the regression models.

SRH transition at three months was significantly associated with one year disability even after control for the BI, FAI, and MMSE at three months. However, SRH status was associated with one year disability only as long as other three months variables were excluded from the model.

Table 5 The prospective association of self rated health status and transition three months after stroke with disability and recurrence free survival at one year: univariate analyses, number (\%)

\begin{tabular}{|c|c|c|c|c|}
\hline & \multicolumn{2}{|c|}{ Disability at one year } & \multicolumn{2}{|c|}{$\begin{array}{l}\text { Recurrence free survival at one } \\
\text { year }\end{array}$} \\
\hline & No $(n=167)$ & Yes $(n=189)$ & Yes $(n=486)$ & No $(n=75)$ \\
\hline \multicolumn{5}{|c|}{ Self rated health status at three months } \\
\hline Excellent & $11(6.6)$ & $3(1.6)$ & $21(4.3)$ & $6(8.0)$ \\
\hline Very good & $40(24.0)$ & $27(14.3)$ & 91 (18.7) & $13(17.3)$ \\
\hline Good & $67(40.1)$ & $61(32.3)$ & $179(36.8)$ & $19(25.3)$ \\
\hline Fair & $40(24.0)$ & $59(31.2)$ & $127(26.1)$ & $22(29.3)$ \\
\hline Poor & $9(5.4)$ & $39(20.6)$ & $68(14.0)$ & $15(20.0)$ \\
\hline & $<0.001$ & & 0.38 & \\
\hline \multicolumn{5}{|c|}{ Self rated health transition at three months } \\
\hline Much better & $9(5.4)$ & $5(2.6)$ & $16(3.3)$ & $0(0.0)$ \\
\hline Somewhat better & $15(9.0)$ & $13(6.9)$ & $39(8.0)$ & $8(10.7)$ \\
\hline About the same & $73(43.7)$ & $49(25.9)$ & $166(34.2)$ & $17(22.7)$ \\
\hline Somewhat worse & $58(34.7)$ & $71(37.6)$ & $175(36.0)$ & $22(29.3)$ \\
\hline Much worse & $12(7.2)$ & $51(27.0)$ & $90(18.5)$ & 28 (37.3) \\
\hline $\mathrm{p}^{*}-1$ & $<0.001$ & & 0.004 & \\
\hline
\end{tabular}


Table 6 The prospective association of self rated health status and transition three months after stroke with disability at one year and recurrence free survival over five years: multivariable analyses*

\begin{tabular}{|c|c|c|c|c|c|c|}
\hline & \multicolumn{2}{|c|}{ Disability at one year } & \multicolumn{4}{|c|}{ Recurrence free survival over five years } \\
\hline & $\begin{array}{l}\text { Odds } \\
\text { ratio }\end{array}$ & $\begin{array}{l}\text { ( } 95 \% \text { confidence } \\
\text { intervals) }\end{array}$ & $\mathbf{p}$ & Hazard ratio & $\begin{array}{l}\text { (95\% confidence } \\
\text { intervals) }\end{array}$ & $\mathbf{p}$ \\
\hline \multicolumn{7}{|c|}{$\begin{array}{l}\text { Self rated health status at } \\
\text { three months } \\
\text { Model } 1\end{array}$} \\
\hline $\begin{array}{l}\text { "Poor" versus "Excellent } \\
\text { to fair" } \\
\text { Model } 2\end{array}$ & 3.91 & (1.76 to 8.71$)$ & $<0.01$ & 1.22 & $(0.85$ to 1.76$)$ & 0.27 \\
\hline $\begin{array}{l}\text { "Poor" versus "Excellent } \\
\text { to fair" } \\
\text { Self rated health transition } \\
\text { at three months } \\
\text { Model } 3\end{array}$ & 2.38 & (0.76 to 7.49$)$ & 0.14 & 1.14 & (0.78 to 1.66$)$ & 0.51 \\
\hline $\begin{array}{l}\text { "Much worse" versus } \\
\text { "Much better to somewhat } \\
\text { worse" } \\
\text { Model } 4\end{array}$ & 5.59 & (2.74 to 11.42 ) & $<0.01$ & 1.75 & (1.29 to 2.38 ) & $<0.01$ \\
\hline $\begin{array}{l}\text { "Much worse" versus } \\
\text { "Much better to somewhat } \\
\text { worse" }\end{array}$ & 6.29 & (2.26 to 17.52$)$ & $<0.01$ & 1.72 & (1.24 to 2.38 ) & $<0.01$ \\
\hline $\begin{array}{l}{ }^{*} \text { All models were adjusted } \\
\text { Index. Models } 2 \text { and } 4 \text { cont } \\
\text { and Mini Mental State Exa }\end{array}$ & for age & $\begin{array}{l}\text { sex, ethnicity, pre-s } \\
\text { o for Barthel Index } \\
\text { at three months. }\end{array}$ & $\begin{array}{l}\text { oke Bart } \\
\text { t three m }\end{array}$ & $\begin{array}{l}\text { hel Index, and } \\
\text { nonths, Frencha }\end{array}$ & $\begin{array}{l}\text { e-stroke Frenchay } \\
\text { Activties Index at thr }\end{array}$ & $\begin{array}{l}\text { Activities } \\
\text { ree month }\end{array}$ \\
\hline
\end{tabular}

The analysis of recurrence free survival over five years included only those patients who had already survived the first three months after stroke (table 6). In 1650 person years 212 failure events were observed-that is, 66 stroke recurrences and 146 deaths. SRH status did not relate to recurrence free survival in multivariate analysis. On the other hand SRH transition showed a stronger association $(p<0.01)$ with recurrence free survival than the three months BI, FAI, and MMSE. Kaplan-Meier curves of recurrence-free survival are given in figure 1.

In a sensitivity analysis half of the patients who rated their health at three months as "much worse" were randomly deleted. The association of SRH transition with one year disability and recurrence free survival remained significant in models 3 and 4 . When SRH transition was dichotomised at a different level ("much better to about the same" compared with "somewhat worse to much worse") results did not change substantially. The association of SRH transition with one year disability in model 3 and 4 remained highly significant $(p<0.01)$, and the association with recurrence free survival was significant in model $3(p=0.05)$ and borderline significant in model $4(p=0.1)$.

\section{DISCUSSION}

This population based study examined prospectively SRH status and SRH transition during recovery from stroke over three years. Items on SRH have been shown to have good reliability, when administered in face to face interviews as in our follow up assessments. ${ }^{22-24}$

The main finding of this study was that single question assessments of SRH transition had good predictive validity. "Much worse" health three months after stroke was significantly associated with one year disability and lower five year recurrence free survival. This was even after controlling for outcome measures across a range of domains such as the Barthel Index, the Frenchay Activities Index, and the Mini Mental State Examination. On the other hand the prospective association of SRH status to disability and recurrence free survival did not reach significance after control for the aforementioned three months measures. It should be acknowledged that the Barthel Index has a severe ceiling effect and is an imperfect measure of disability one year after stroke. ${ }^{17}{ }^{18}$ Furthermore, the dichotomisation of SRH status, and SRH transition was done post hoc resulting in increased error chances. The results suggested that "Much
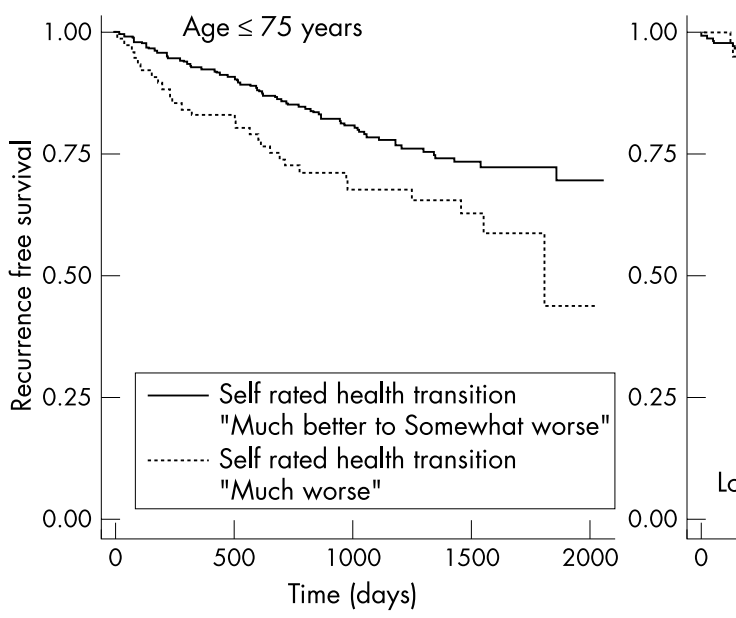

Age $<75$ years
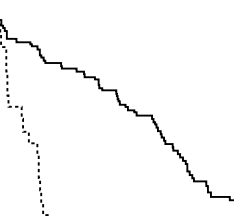

:
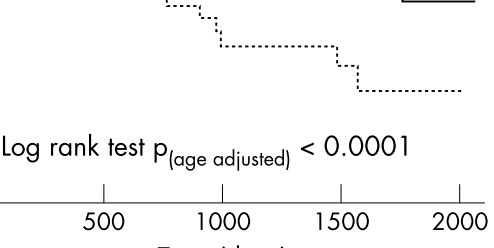

Figure 1 Recurrence free survival over five years after first ever stroke by self rated health transition among 561 stroke patients. 
worse" health three months after stroke in particular was associated with subsequent poor outcome. Differences in outcome between all other self ratings ("Much better" to "Somewhat worse" health) were not substantial.

Studies comparing SRH status and SRH transition are sparse. The only other study conducted in this area corroborates our results as it found SRH decline and not SRH status significantly associated with survival. ${ }^{25}$

This study could assess the sensitivity of SRH to major medical events only indirectly, because no pre-stroke measures of SRH were available. It was assumed that a sensitive item would lead to different responses shortly after the stroke compared with later on. Responses to the item on SRH transition showed a health decline significantly more often three months after stroke than at all subsequent follow ups. The response to the item on SRH status, however, did not change during follow up. These findings are in keeping with one prospective study, which has demonstrated that SRH status remains almost the same before and after medical events such as stroke, myocardial infarction, or hip fracture. ${ }^{12}$

Apparently subjects establish perceptions of their own health status over many years and tend not to revise these perceptions in the wake of a recently experienced acute illness. This tendency might be explained by people's desires to hold positive beliefs about themselves. ${ }^{26}$ However, when patients are specifically asked to make a temporal comparison (SRH transition), they realise the decline in health attributable to an illness like stroke and the improvement in health during recovery. This is why items of SRH transition might be more useful indicators of changes in health attributable to an acute illness such as stroke than items of SRH status.

Patients aged over 75 years of age gave more favourable self ratings of both their health status and health transition compared with younger patients. This was in contrast with the observation that elderly patients had higher losses in the Barthel and Frenchay Activities Index after stroke than younger patients. ${ }^{27}$ Other researchers have also reported more optimistic health ratings among the elderly population and a decrease in the association between "objective" and "subjective" health indicators with age. ${ }^{28} 29$

Caribbean and African stroke patients gave less favourable self ratings of their health status and health transition. This could partially be explained by the fact that they were younger and had more disabling strokes than the white patients. ${ }^{27}$ The association between ethnicity and both SRH status and SRH transition became insignificant, when it was adjusted for age and the three months BI and FAI (data not shown). Hence, it seems unlikely that there were major differences in the process of evaluating health between ethnic groups.

Although these analysis controlled for cognitive function (MMSE), no adjustment was made for mood. Some authors have argued that depression or low self esteem can affect $\mathrm{SRH}$, whereas others have found SRH to be most closely associated with physical health parameters, rather than with general considerations of morale or self image. ${ }^{3031}$

One problem in monitoring recovery after stroke is that no instruments are available to measure changes in overall health and quality of life. Longitudinal studies obtaining repeated measures with the same instrument (for example, SF-36, EuroQol), have proved problematic, as measurement errors in some of the subscales can be of the same magnitude as the expected changes. ${ }^{33}$ This study demonstrated the advantage of one item asking specifically for a health transition over a general item on health status in the study of recovery from stroke. This may point the direction for the future development of instruments in research on stroke recovery. Instruments should be designed for the cross

\section{Key points}

- Self rated health is an indicator that provides valid information after stroke in addition to objective outcome measures such as the Barthel Index.

- Items on self rated health transition may better reflect deterioration and recovery after an acute health event such as stroke than items on self rated health status.

- Patients reporting a health transition to "much worse" three months after stroke have an increased risk of disability at one year and decreased chances to survive free of stroke recurrence over the next five years.

- The usefulness of items on self rated health is limited in research on severe and disabling diseases as almost one fifth of patients experience difficulties with completion of these simple single question items.

sectional assessment of health transitions in different dimensions, which might help to avoid costly longitudinal studies.

The representativeness of data from the South London Community Stroke Register is superior to most other studies on stroke outcome. Previous studies have not often been population based, ${ }^{34}$ or the case ascertainment has been based on patient self report possibly introducing bias. $^{8}$ The proportion of three months survivors who participated in our follow up was high at $90 \%$. However, almost one in five participants could not complete the items requiring patient cooperation. This might be accounted for by the ethnic diversity of the study sample with a high proportion of non-English speakers, as well as the nature of the studied disease that affects brain function. Health ratings by proxies were not used, as significant differences between patients and proxies have been reported. ${ }^{33}$ As a result this study could not include a considerable proportion of stroke survivors. This has been an inherent problem with other studies in stroke research, which have tried to measure quality of life and take the patients' own perceptions into account. $^{23}{ }^{24}$

\section{ACKNOWLEDGEMENTS}

The study was principally funded by the Northern and Yorkshire Region Research and Development Programme. The design, execution and report of the study were independent of sponsors.

\section{Authors' affiliations}

T Hillen, S Davies, C D Wolfe, Division of Primary Care and Public Health Sciences, Guy's, King's and St Thomas' School of Medicine, King's College, London, UK

A G Rudd, Elderly Care, Guy's and St Thomas' Hospital Trust, London, UK

T Kieselbach, Institute for the Psychology of Work, Unemployment and Health, University of Bremen, Germany

\section{REFERENCES}

1 Krakau I. Perception of health and use of health care services in a Swedish primary care district. A ten year's perspective. Scand J Prim Health Care 1991;9:103-8.

2 Moller L, Kristensen TS, Hollnagel H. Self rated health as a predictor of coronary heart disease in Copenhagen, Denmark. J Epidemiol Community Health 1996;50:423-8.

3 McGee DL, Liao Y, Cao G, et al. Self-reported health status and mortality in a multiethnic US cohort. Am J Epidemiol 1999:149:41-6.

4 Idler EL, Benyamini Y. Self-rated health and mortality: a review of twentyseven community studies. J Health Soc Behav 1997;38:21-37.

5 Hoeymans N, Feskens EJ, Kromhout D, et al. The contribution of chronic conditions and disabilities to poor self- rated health in elderly men. J Gerontol A Biol Sci Med Sci 1999;54:501-6. 
6 Schuling J, de Haan R, Limburg $M$, et al. The Frenchay Activities Index. Assessment of functional status in stroke patients. Stroke 1993;24:1173-7.

7 Roberts L, Counsell C. Assessment of clinical outcomes in acute stroke trials. Stroke 1998:29:986-91.

8 Wyller TB, Holmen J, Laake P, et al. Correlates of subjective well-being in stroke patients. Stroke 1998;29:363-7.

9 Ween JE, Alexander MP, D'Esposito M, et al. Factors predictive of stroke outcome in a rehabilitation setting. Neurology 1996;47:388-92.

10 Wilkinson PR, Wolfe CD, Warburton FG, et al. A long-term follow-up of stroke patients. Stroke 1997:28:507-12.

11 Pedersen PM, Jorgensen HS, Nakayama H, et al. Comprehensive assessment of activities of daily living in stroke. The Copenhagen Stroke Study. Arch Phys Med Rehabil 1997;78:161-5.

12 Wilcox VL, Kasl SV, Idler EL. Self-rated health and physical disability in elderly survivors of a major medical event. J Gerontol B Psychol Sci Soc Sci 1996;51:96-104.

13 Stewart JA, Dundas R, Howard RS, et al. Ethnic differences in incidence of stroke: prospective study with stroke register. BMJ 1999;318:967-71.

14 Hillen T, Dundas R, Lawrence $E$, et al. Antithrombotic and antihypertensive management 3 months after ischemic stroke: A prospective study in an inner city population. Stroke 2000;31:469-75.

15 WHO Task Force on Stroke and other Cerebrovascular Disorders. Recommendations on stroke prevention, diagnosis, and therapy. Report of the WHO Task Force on Stroke and other Cerebrovascular Disorders. Stroke 1989;20:1407-31.

16 Lawton MP, Brody EM. Assessment of older people: self-maintaining and instrumental activities of daily living. Gerontologist 1969:9:179-86.

17 Wolfe CD, Taub NA, Woodrow EJ, et al. Assessment of scales of disability and handicap for stroke patients. Stroke 1991;22:1242-4.

18 Wellwood I, Dennis MS, Warlow CP. A comparison of the Barthel Index and the OPCS disability instrument used to measure outcome after acute stroke. Age Ageing 1995;24:54-7.

19 Bamford J, Sandercock P, Dennis M, et al. A prospective study of acute cerebrovascular disease in the community: the Oxfordshire Community Stroke Project-1981-86. J Neurol Neurosurg Psychiatry 1990;53:16-22.

20 Teasdale G, Murray G, Parker L, et al. Adding up the Glasgow Coma Score. Acta Neurochir Suppl (Wien) 1979;28:13-16.
21 Burn J, Dennis M Bamford J et al. Long-term risk of recurrent stroke after a first-ever stroke. The Oxfordshire Community Stroke Project. Stroke 1994;25:333-7.

22 Parker SG, Peet SM, Jagger C, et al. Measuring health status in older patients. The SF-36 in practice. Age Ageing 1998:27:13-18.

23 Dorman P, Slattery J, Farrell B, et al. Qualitative comparison of the reliability of health status assessments with the EuroQol and SF-36 questionnaires after stroke. United Kingdom Collaborators in the International Stroke Trial. Stroke 1998;29:63-8.

24 Anderson C, Laubscher S, Burns R. Validation of the Short Form 36 (SF-36) health survey questionnaire among stroke patients. Stroke 1996;27:1812-16.

25 Deeg DJ, van Zonneveld RJ, van der Maas PJ, et al. Medical and social predictors of longevity in the elderly: total predictive value and interdependence. Soc Sci Med 1989;29:1271-80.

26 Suls J, Marco CM, Tobin S. The role of temporal comparison, social comparison, and direct appraisal in the elderly's self-evaluations of health. J Appl Social Psychol 1991;21:1125-44.

27 Lawrence ES, Coshall C, Dundas R, et al. Estimates of the prevalence of acute stroke impairments and disability in a multiethnic population. Stroke $2001 ; 32: 1279-84$.

28 Hoeymans N, Feskens EJ, Kromhout D, et al. Ageing and the relationship between functional status and self-rated health in elderly men. Soc Sci Med 1997:45: 1527-36.

29 Dening TR, Chi LY, Brayne C, et al. Changes in self-rated health, disability and contact with services in a very elderly cohort: a 6-year follow-up study. Age Ageing 1998;27:23-33.

30 Mulsant BH, Ganguli M, Seaberg EC. The relationship between self-rated health and depressive symptoms in an epidemiological sample of communitydwelling older adults. J Am Geriatr Soc 1997;45:954-8.

31 Tissue T. Another look at self-rated health among the elderly. J Gerontol 1972;27:91-4

32 Idler EL. Age differences in self-assessments of health: age changes, cohort differences, or survivorship? J Gerontol 1993;48:289-300.

33 Dorman PJ, Waddell F, Slattery J, et al. Are proxy assessments of health status after stroke with the EuroQol questionnaire feasible, accurate, and unbiased? Stroke 1997; 28: 1883-7.

34 King RB. Quality of life after stroke. Stroke 1996;27:1467-72. 